\title{
Study on Variation in the Origin of Renal Artery.
}

\author{
${ }^{1}$ Mr.Kishwor Bhandari, ${ }^{2}$ Mrs. Sanju Acharya ${ }^{3}$ Mr. Prakash Mane, \\ ${ }^{4}$ Dr. Aruna Mukherjee, \\ ${ }^{1,3,4}$ Department of Anatomy, MGM Medical College, Sector-1, Kamothe, Navi Mumbai-410209. \\ ${ }^{2}$ Department of Physiology,MGM Medical College,Sector-1, Kamothe, Navi Mumbai-410209
}

\begin{abstract}
With the increasing numbers of vascular reconstructions and various surgical and radiologic techniques the knowledge of the variations of renal artery has grown its importance. The present study was carried out on 129 renal arteries. The origin of renal artery with reference to lumbar vertebrae was studied. The most frequent position of origin of renal artery was found at the level of $L 1$ which was $55.81 \%, L 1 \& L 2=$ $32.56 \%, L 2=11.63 \%$.
\end{abstract}

Key words: Renal artery, abdominal aorta, vertebral level L1.

\section{Introduction.}

Significance in the variations of the origin of the renal artery has gained importance with the advent of renal transplant. The variations in origin of renal arteries at different levels of vertebrae results in technical limitations in kidney transplantation as the origin of renal artery is important in selecting the appropriate kidney (left or right) for laparoscopic procurement.

According to anatomical descriptions, each kidney is supplied by a renal artery which is a branch of abdominal aorta. ${ }^{1}$ Abdominal aorta lies on the left side of the vertebral column, therefore the right renal artery is longer than the left renal artery. ${ }^{2}$ The renal arteries which are supplying the blood to the kidneys take about $20 \%$ of the cardiac output. ${ }^{3}$ Every minute about $1200 \mathrm{ml}$ of blood passes through the kidneys. ${ }^{4,5}$ The blood reaching the kidneys through the renal arteries is needed not only to supply the renal parenchyma but also to take part in the renal filtration.

Renal arteries originates at right angle from the abdominal aorta just below the superior mesenteric artery at the level of intervertebral disc between L1 and L2 vertebra ${ }^{6}$ but very rarely the main renal artery originates from superior mesenteric artery, ${ }^{7}$ coeliac trunk, ${ }^{8}$ common iliac artery, external iliac artery, gonadial artery. ${ }^{9}$ Extra renal artery if present usually originates from abdominal aorta. This cadaveric study was focused on the existence and the frequency of variations of origin of renal arteries which are becoming more important due to increase in interventional radiological and urological procedures.

\section{Materials and methods.}

The study was performed in the Department of Anatomy of Medical Colleges of Navi Mumbai. Fifty human cadavers (preserved in 10\% formaldehyde) irrespective of sex were dissected. A total of 129 renal arteries(main and accessory) were surveyed according to the source of origin and position in relation to the vertebrae (Vertebral body or intervertebral disc).The aortic branch of larger caliber was considered as the main renal artery and the aortic branch of smaller caliber was considered as the accessory renal artery. The method of dissection was done according to the "Cunningham's Manual of Practical Anatomy". ${ }^{10}$ The origins of renal arteries was tabulated and statistically analyzed.

III. Result.

Table: 1. Origin of renal arteries at vertebral levels on left side.

\begin{tabular}{|l|l|l|l|}
\hline C.N. & Vertebral Level & On left side & On left In \% \\
\hline 1. & L1 & 25 & $36.76 \%$ \\
\hline 2. & L1 \& L2 & 30 & $44.12 \%$ \\
\hline 3. & L2 & 13 & $19.12 \%$ \\
\hline
\end{tabular}


Table: 2. Origin of renal arteries at vertebral levels on right side.

\begin{tabular}{|l|l|l|l|}
\hline C.N. & Vertebral Level & On Right Side & On Right In \% \\
\hline 1. & L1 & 47 & $77.5 \%$ \\
\hline 2. & L1 \& L2 & 12 & $19.67 \%$ \\
\hline 3. & L2 & 2 & $3.28 \%$ \\
\hline
\end{tabular}

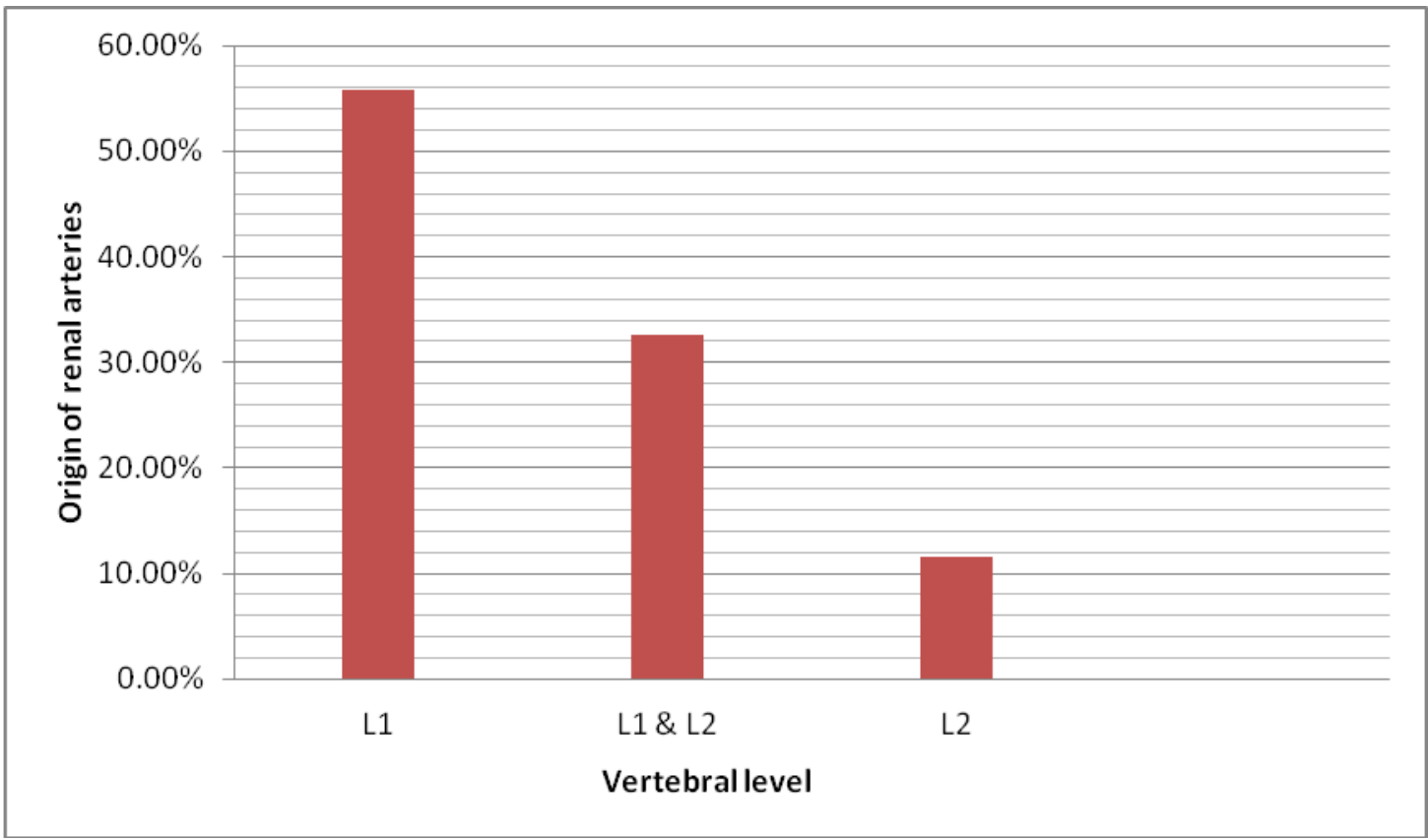

Fig.1: Bar Chart Showing Origin of Renal Arteries at Vertebral levels.

\section{Discussion.}

Variations in renal arteries are not uncommon. Prakash et al. in 2011 studied the abdominal aorta and its branches. They found the origin of renal artery at L1on left side was $82 \%$ and on right side was $80 \% .11$. In our study the left and right renal arteries originating at the level of L1 was $36.76 \%$ and $77.5 \%$ respectively. Neil Pennington et al. in 2005 reported the origin of renal arteries at the lower third of the body of vertebrae L1. But they didn't mention the percentage. 12 Rao et al. in 2011 presented a case report in which the aberrant right renal artery originated at the level of lower border of L1 vertebrae along with the origin of normal right renal artery.13 Palmieri et al in 2011 reported the origin of renal arteries from the aorta with greater frequency at intervertebral disc between L1 and L2, on the right side $38.85 \%$ and on the left.14 $35.7 \%$ In the present study the renal arteries originated at intervertebral disc between L1 and L2, on right and left side it was $19.67 \%$ and $44.12 \%$ respectively. Renal artery origin at L2 has been reported singly but the studies have not included a percentile value. Srijit Das in 2008 mentioned the left renal artery originating at the level of second lumbar vertebrae. ${ }^{15}$ In the present study the renal artery originating at the level of vertebrae L2 was $11.63 \%$.

Gray's Anatomy $40^{\text {th }} \mathrm{ed}$ mentions that the origin of the renal artery is below the origin of the superior mesenteric artery which matches with the present study. ${ }^{16} \mathrm{We}$ found all the renal arteries originating below the superior mesenteric artery. Saldarriaga et al. in 2008 reported the right renal artery was proximal to the left renal artery in $49.2 \%$ and the left renal artery was proximal to the right renal artery in $16.4 \% .{ }^{17}$ In our study the right renal artery often originated proximal to the left renal artery (At L1 level $77.5 \%$ on right \& $36.76 \%$ on left). In literature there are cases of rare variations of origin of the main renal artery from the superior mesenteric artery ${ }^{7}$ celiac axis ${ }^{8}$, most cranial part of abdominal aorta ${ }^{41}$. No such origin was found in the present study.

\section{Conclusion.}

With the advent of laparoscopic renal surgeries and donor nephrectomies, it becomes mandatory for the surgeon to understand the level of origin of renal artery from the abdominal aorta. Renal transplant may be jeopardized by the presence of abnormal origin of renal artery. Therefore, considering the variation of origin of renal artery, angiographic study of renal artery must be done in order to perform successful renal transplant. 


\section{Abbreviations}

L1: First Lumbar vertebra.

L1 \& L2: Intervertebral disc.

L2: Second Lumbar Vertebra

\section{References.}

[1]. Snell R.S. Clinical anatomy ${ }^{7 \text { th }}$ ed. Philadelphia; USA: Lippincott Williams \& Wilkins.2004.p. 283

[2]. Sing Indirbir. Text book of anatomy vol 2, $5^{\text {th }}$ ed. New Delhi; India: Jaypee Brothers; 2011.

[3]. Gary AT, Kevin TP. Anatomy \& physiology $2^{\text {nd }}$ ed. USA:Mosby;1993.

[4]. Tortora GJ, Anagnostakos NP. Principles of anatomy and physiology $6^{\text {th }}$ ed.

[5]. NewYork:Harper Collins Publishers.p. 832.

[6]. Sahana SN. Human anatomy Vol II, $3^{\text {rd }}$ ed.Calcutta:K.K.Publishers;1980. P.

[7]. 352

[8]. Keith L. Moore, Arthur F Dalley, Anne M.R.Agur. Clinically Oriented Anatomy $6^{\text {th }}$ ed. Lippincott Williams \& Wilkins.2010.

[9]. Tuncay Colak, Belgin BAMAC,Ayden Ozbek,Umit Naci Gundogmus. A Report of Unusual Origin Of Right Renal Artery .International journal of Anatomical variations.2011 4:95-97.

[10]. S Nachiappan, S Franks, P Thomas. Single ectopic main right renal artery originating from the coeliac axis. Journal of Surgical Case Reports. 2011. 12:10

[11]. Ronald A. Bergman, Adel K. Afifi, MS Ryosuke Miyauchi. Anatomy Atlases. Renal Arteries. Illustrated Encyclopedia of Human Anatomic Variation: Opus II: Cardiovascular System: Arteries: Abdomen.

[12]. G.j.Romanes. Cunningham's Manual of Practical Anatomy $15^{\text {th }}$ ed. New York: Oxford University Press.2000. vol 2.

[13]. Prakash P, Mokhasi V, Rajini T, Shashirekha M. The abdominal aorta and its branches: anatomical variations and clinical implications. Folia Morphol (warsz).2011 nov:70(4);282-6.

[14]. Pennington N,Soames RW. The anterior visceral branches of the abdominal aorta and their relationship to the renal arteries. Surgical and radiologic anatomy. Vol 27,number 5,395-403

[15]. Rao TR, Rachana. Aberrant renal arteries and its clinical significance: A case report. International journal of anatomical variations. (2011), 4:37-30

[16]. Palmieri BJ, Petroianu A, MG TCBC, silva LC, Andrade LM, Alberti LR. Study of arterial pattern of 200 renal pedicle through angiotomography. Rev.Col.Bras.Cir. vol. 38. No.2. Rio de Janeiro. Mar/April 2011.

[17]. Das Srijit. Anomalous renal arteries and its clinical implications.Bratisl lek listy 2008; 109(4) p.182-184.

[18]. Susan S,Neil RB, Patrica C. Gray's Anatomy 40 ${ }^{\text {th }}$ ed. London: Churchill Livingstone. 2008. p. 1231.

[19]. Saldarriaga B,Pinto SA, Ballesteros. Morphological expression of the renal artery. A direct anatomical study in a Colombian halfcast population. Int.J.Morphol.,26(1):31-38,2008

[20]. Garti IA, Meiraz DA. Ectopic origin of main renal artery. Urology, vol 15, Issue 6, p.627-629, June 1980. 